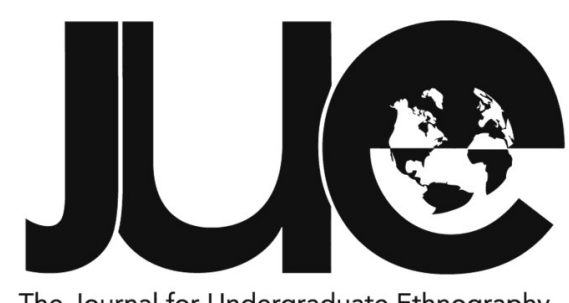

\title{
Applications of Biopower to NGO-Donor Partnerships for HIV Prevention in Jordan
}

\section{Zachary Gallin}

Georgetown University, zjg8@georgetown.edu

\section{ABSTRACT}

NGOs serving marginalized groups in the developing world often lie under heavy donor influence, so they must toe the line between compliance with and resistance against their funders to best promote the well-being of their beneficiaries. Jordanian health NGOs have grappled with these power dynamics since the 1990s when donor countries began pouring money into Jordan's private sector as part of structural adjustment. I use ethnographic data from a Jordanian HIV prevention NGO to analyze how Foucault's (1978) theory of biopower applies to international NGO-donor relationships. I argue that the international aid chain transforms NGO staff and the populations they serve into biological subjects expected to adhere to norms set by American and European donors. Biopower manifests differently depending on donor approaches to project implementation, monitoring, and evaluation. 
W hile conducting ethnographic fieldwork at a Jordanian HIV prevention NGO, which I will call Majhul, I listened in on a video call between the NGO's staff and a representative from a British donor organization. The donor representative spoke entirely in English, so Majhul's one English-speaking employee was responsible for communicating with him. Majhul's manager, who was on the call but did not speak English, followed along as best as he could. The donor representative expressed that his organization wanted to give Majhul a grant. He then asked for various English-language documents, and he explained that representatives from his organization would travel to Jordan soon to visit Majhul and talk with its staff. He emphasized that his organization would aim to work with Majhul on improving its services over a prolonged period, so he would visit Majhul many times in the future to assess their long-term progress.

Towards the end of the call, Majhul's Englishspeaking employee told the representative that they would email him all of the documents he requested and send him their goals for improvement by the end of September. The representative responded that this would be okay, but it would cause a time crunch, as he must visit Majhul before the end of the calendar year. Majhul's manager wrapped up the call by saying in broken English that he did not want the grantor to come to Jordan and tell Majhul how to do its job. Rather, he hopes that Majhul's staff will be able to tell the donor what Majhul needs. The donor representative agreed with Majhul's manager, then the call ended.

This vignette and many others from Majhul's relationships with its donors reveal how many of the funding challenges facing public health NGOs in the developing world can be understood through biopower, defined by Michel Foucault (1978) as a technology of power in which the governed population becomes a biological product that governing actors use to reap desired outcomes. Because funding becomes the principal instrument of power over public health NGOs, donor policies shape the programming these NGOs can provide and the populations they can serve. The specific dynamics of power exertion vary by donor, and Majhul has learned to navigate this terrain while also promoting the long-term well-being of its beneficiaries.

In this context, the term "beneficiaries" describes the population served by Majhul. While terms like "client" and "partner" could be substituted, the staff of both Majhul and its donors exclusively used the term "beneficiary" during my research period. "Client" and "partner" would connote that the populations served have a dialectic relationship with Majhul in which they hold sway over the services they receive. "Beneficiary" loses this connotation and suggests only that Majhul benefits these populations.

In this article, I draw on my fieldwork at Majhul to reveal how donor-NGO relations in the field of HIV prevention provide a window into the everyday workings of biopower. I elucidate how Majhul's barriers to successful project implementation are interwoven with the at times overbearing norms set by donors, which Majhul navigates by pairing compliance with advocacy. I then highlight case studies from Majhul's relationships with two of its most important international funders. I contrast these relationships, using each case study as an example of how biopower underlies important aspects of NGO-donor partnerships.

\section{Methodology}

I first visited Majhul in the summer of 2018, when I met its manager while exploring Jordan's HIV prevention movement. I returned in the summer of 2019 to conduct ten weeks of ethnographic fieldwork. Prior research has relied on quantitative data to describe HIV in Jordan (Al-Khasawneh et al. 2012; Al-Khasawneh et al. 2014; Alkaiyat et al. 2014; Marnicio 2016; Nawafleh, Francis, and Chapman 2005). Ethnographic research provides a window into 
the everyday practices that define donor-NGO relationships, the power structures NGO staff and beneficiaries must navigate, and how these structures exemplify biopower as a theoretical explanation for international aid.

The research presented here draws on over 360 hours of participant observation at Majhul, as well as analysis of Majhul's printed and online media about the needs of its beneficiaries. I collected data from nearly all of the settings Majhul's staff work in, including its health center, its administrative floor, and other conference centers and NGO sites across Jordan. I also conducted semi-structured interviews with Majhul's employees. I sought to interview a wide range of part-time and fulltime staff, so I asked nearly every staff member I met. Ultimately, I was able to interview six of the approximately fourteen full-time and part-time staff members. All interviewees read through an informed consent script and orally expressed consent prior to their interview.

I triangulated the participant observation, staff interviews, and media I collected to explore Majhul's relationship with foreign donors, tracing how power flowed from donors through Majhul to its staff and beneficiaries in often multifaceted and unexpected ways. I found that donor use of earmarked funding and upward accountability compelled Majhul to follow donor norms when providing health services to its beneficiaries; this exemplifies the presence of biopower in NGO-donor relationships.

Some of the limitations of my study include the limited availability of some of Majhul's staff, the reluctance of some staff members to agree to be interviewed, and temporal constraints on my participant observation period. I had limited opportunities to engage with some staff members because many staff work part time, staff often work from outside of Majhul's main offices, and some staff left Majhul during my research period. Additionally, Jordan has a history of limiting freedom of expression, so staff were likely cautious about making public remarks that could be viewed as critical of the government even though my research was not of an overtly political nature (Wiktorowicz 2002). As an American researcher, I was advantaged in that I could position myself as separate from the Jordanian government. However, I am similar to many of Majhul's donors in that I'm American and English-speaking, so Majhul's management may have viewed my research as a way to recruit donors. I emphasized that participation in my study was not linked to financial compensation, but Majhul's staff may have nevertheless regulated their behavior and comments around me to portray Majhul in a positive light.

\section{Global Health Funding in the Late 20th and Early 21st Centuries}

The current relationships between Arab NGOs and their international donors were shaped by the World Bank's structural adjustment programs of the 1980s and 1990s. Structural adjustment exacerbated inequality throughout the Arab world, simultaneously increasing the need for NGOs and sparking popular distrust of intergovernmental aid. Although Arab countries were widely touted by the World Bank as "success stories," many of these countries were forced to cut their social safety nets, pushing much of their populations into abject poverty (El-Said and Harrigan 2014). Healthcare increasingly came to be seen as a commodity rather than a right. It was privatized and user fees were introduced, as in many other countries across the developing world (Basilico et al. 2013; Packard 2016).

The World Bank sought to reform Jordan's health system through privatization (Quinn et al. 2001). It removed government responsibility for public health and shifted power over the health sectors towards private actors, chief among them foreign donors. This led to Jordan's private healthcare sector ballooning; the number of private hospital beds in the country rose by 28\% between 1988 and 1994 (Kumaranayake 1998). At the same time, it reversed many of the Jordanian government's successes in public health from the 1980s, hitting Jordan's marginalized and vulnerable populations the hardest (Baylouny 2008; Dejong 1995). It therefore set the stage for the creation of NGOs like Majhul, which are devoted to Jordan's vulnerable populations.

The World Bank was the largest distributor of global health funding worldwide by the early 2000s (Packard 2016). At this time, it began to 
push for additional monitoring of and grassroots accountability for the initiatives it funded, encouraging a vision of "health investments" worldwide. Health investment became one of the dominant paradigms of global health and development (Packard 2016, 287).

The early 2000s also saw a massive, unprecedented surge in global support for HIV/ AIDS prevention. This support culminated in the launch of the Global Fund, a key donor for Jordan's HIV prevention NGOs. Many of the Global Fund's core values align with those of the World Bank. For instance, as Packard (2016) explains, the Global Fund usually mandates that local NGOs and other private actors be stakeholders in its grants, and it has distinguished itself through its use of extensive monitoring and evaluation to demand accountability from its grantees. Packard (2016) argues that the Global Fund's neglect of the existing health systems in countries it served and its distrust of local governments furthered some of the consequences of structural adjustment: governments continued to lose power over healthcare to the private sector, and health became increasingly medicalized and commodified.

The Global Fund's emphasis on HIV funding has also faced criticism for propagating "HIV exceptionalism": the notion that HIV is an exceptional health crisis requiring a funding stream separate from the rest of global aid. This has tended to create "silos" of funding, divorcing HIV from related social and medical services. HIV exceptionalism has had at best a mixed and controversial effect on health systems across Africa (Benton 2015; Grépin 2012; Nguyen 2010). I found through my research at Majhul that HIV exceptionalism has also challenged Jordanian NGOs by creating silos of HIV prevention funds separate from funding for related issues like human rights and poverty prevention in Jordan.

HIV exceptionalism was one of many recent controversies in the provision of international AIDS funding. For instance, UNAIDS declared in 2015 that international funding could "end HIV by 2030." Das and Horton (2018) argue that this declaration set the stage for global complacency around the HIV pandemic, as it led governments and NGOs to erroneously believe that the current international HIV/AIDS prevention efforts are enough to stop HIV's spread. Consequently, global HIV funding decreased even as the global population living with HIV grew. According to Majhul's director, the "end HIV by 2030" declaration decreased both foreign and domestic donors' willingness to prioritize HIV prevention in Jordan. UNAIDS also promoted a problematic "post-AIDS" discourse, with catchphrases like "zero new HIV infections, zero discrimination, and zero AIDSrelated deaths" and the "90-90-90" campaign (90\% diagnosed; $90 \%$ on treatment; $90 \%$ virally suppressed). This discourse oversimplifies the ongoing challenges in global HIV prevention and treatment, as it neglects the diversity of lived experiences that people living with HIV face. Therefore, it fails to acknowledge that HIVrelated discrimination and access to HIV diagnosis and treatment vary greatly by region and demographic group, so a "post-AIDS" world remains far out of reach for many (Walker 2017).

\section{Donor Policies as they Relate to HIV Prevention}

American and European donors often set norms around global development that NGOs in developing countries must follow in order to receive funds, with funding conditional on NGO behavior (Bornstein 2006; Ebrahim 2002; Mueller-Hirth 2012; Reith 2010; Wallace, Bornstein, and Chapman 2007). One of the most important of these norms is the rational management approach, a "business model" for development described by Tina Wallace, Lisa Bornstein, and Jennifer Chapman (2007). They explain that according to rational management theory, development progress is marked by the completion of specific steps that lead to the achievement of larger goals when followed linearly. Progress is therefore controlled, predictable, and trackable by monitoring success indicators through a "logical framework," a document that outlines the project's goals, timetables, and indicators of success. This framework is drawn up before the project's inception, and then closely followed throughout the project. Wallace, Bornstein, and Chapman (2007) suggest that rational management is attractive to donors because it 
enables them to easily track the effectiveness of their donations via monitoring and evaluation. Through the monitoring of success indicators, donors align with the World Bank's vision of "health investments"; donations are perceived not as charity but as investments in foreign "implementing partner" NGOs. Return on these "investments" is assessed through fulfillment of success indicators.

Wallace, Bornstein, and Chapman (2007) are highly critical of the donor focus on upward reporting and accountability that comes alongside rational management. They argue that reporting within the logical framework is onerous and time-intensive, as reports must often be written in English, reporting structures are not standardized among donors, and donor management styles and reporting demands are ever-changing. Hummelbrunner (2010) echoes many of their arguments, attacking logical frameworks' tendency to oversimplify objectives, decrease project flexibility, and result in a form of "tunnel vision" where the sole focus of donors and implementing partners alike is to achieve predetermined results in order to deliver a "return" on the "investments" donors make. Wallace, Bornstein, and Chapman's (2007) and Hummelbrunner's (2010) findings are reflected in various ethnographic studies of African NGOs (see Bornstein 2006; Mueller-Hirth 2012; Porter 2003; Nguyen 2010; Reith 2010).

\section{HIV Prevention in Jordan}

Intense stigma and decades of neglect have limited the body of research on HIV in Jordan. Only eight social and behavioral studies had been published on HIV in Jordan as of 2012, and these studies were, for the most part, confined to specific, ungeneralizable datasets (AlKhasawneh et al. 2012). Since then, only three more academic articles and one working paper have been released. These studies predominantly use ethnography to explore perceptions of HIV in various subsets of the Jordanian public. For instance, Al-Khasawneh et al. published two studies about Jordanians' knowledge of and attitudes towards HIV. The first (2013) study focuses on Jordanian youth ages 14-25, while the second (2014) focuses on students and staff at two Jordanian universities. These studies are complemented by an article on HIV perceptions among Jordanian men who have sex with men (MSM) (Alkaiyat et al. 2014) and a working paper about HIV education for Jordan's youth (Marnicio 2016). No scholarly ethnographies of HIV prevention NGOs in Jordan have ever been published.

HIV data collected by the Jordanian government and by Jordanian NGOs, who usually work with or under the surveillance of the government, is often marred by bias. This bias is apparent in Jordan's Global AIDS Response Progress Reports, which synthesize various government-sponsored studies on HIV. The most recent progress report cites data with small or skewed sample sizes and selectively presents findings to portray the government in a favorable light (Global AIDS Response Progress Reporting: Country Progress Report 2014).

Larger-scale reviews of HIV across the Middle East and North Africa (MENA) region produce conflicting results. While major discrepancies exist in studies regarding HIV prevalence and risk behaviors in different populations, cities, and countries in MENA, most scholars and institutions worldwide agree that MENA is one of the only world regions where rates of HIV transmission and death from AIDS continue to increase (Abu-Raddad et al. 2010; Mumtaz, Riedner, and Abu-Raddad 2014).

My research complements the existing literature by using ethnography to highlight the everyday practices of an NGO at the forefront of HIV prevention and the work its staff must do to navigate the sometimes-conflicting norms established by international donors. I use case studies from Majhul's relationships with two of its donors to reveal how Foucauldian biopower plays a role in the imposition of donor norms.

\section{Majhul's Structure, Mission, Values, and Programming}

Majhul was founded with the mission to support the health of Jordan's marginalized and vulnerable at both the individual and the population level. It provides a web of support services focused upon HIV prevention, catering its services to "key populations" (KPs) that are determined by Majhul and its donors to be at high risk for HIV transmission. The staff of Majhul and its donors use the term "KPs" to 
define demographic groups that they expect their beneficiaries to fit into. Biopower manifests in the use of this term, as individuals only join "KPs" when they meet socio-biological criteria such as gender (female), sexuality (MSM), or disease (HIV-positive). Through the lens of biopower, the bodies of individuals with these traits are subject to surveillance and management. Majhul's KPs include refugee women, gay men, sex workers, injecting drug users, and people living with HIV.

Majhul's ideology centers on the belief that structural violence (Farmer 2003) in the form of unemployment, stigma, and poverty undergirds KPs' struggles to achieve health equity. Majhul's management thus believe that a focus on the social context of HIV transmission better enables them to serve KPs. This focus also protects Majhul from stigmatization as a gay men's health center, thus helping it survive in an unforgiving cultural environment. Most of the health workers I interviewed cited stigma towards KPs as a major challenge for Majhul.

Like all Jordanian NGOs, Majhul must contend with the Jordanian government, which uses various laws and policies to constrain the agency of Jordanian civil society (Wiktorowicz 2002). Majhul positions itself as a resource for the Jordanian Ministry of Health's National Program to Combat AIDS, where members of its leadership used to work. Therefore, it partially acquiesces to government power, sacrificing some of its autonomy. Yet, it also gains power by capitalizing on the government's resources and legitimacy, as both donors and government bureaucrats are more likely to support NGOs that have established ties with the government.

Majhul emphasizes the links between HIV prevention and the rights of KPs, aligning itself with a growing body of social theory on the linkages between health, development, and human rights (Mann et al. 1994; Uvin 2004). Majhul uses its autonomy as a governmentaffiliated NGO to set itself apart from the predominant cultural discourse that ignores or disavows the rights of KPs. Many of Majhul's services are meant to help KPs access their social and economic rights, and Majhul works closely with partner NGOs to provide beneficiaries with comprehensive support.

\section{Biopower and Majhul's Relationships with Donors}

Foucault (1978) describes biopower as the process by which governing bodies exert power over individuals and populations by defining and promoting traits that constitute a "model" body while seeking to "correct" any deviation from these traits. Through this lens, funding becomes the principal instrument of power over Majhul. International donors selectively allocate, monitor, and manage funds, while the Jordanian government either allows or restricts the transfer of funds between donors and NGOs. International donors and the Jordanian government set norms that Majhul must follow to maintain funding. They therefore create certain types of biological "subjects": bodies subject to their scrutiny and under pressure to conform with their demands. For instance, they establish norms for a "model health worker" or "model beneficiary" and seek to correct deviation from these norms.

International donors and the Jordanian government each compel Majhul to follow their own norms, which often conflict with one another. International donors often base their norms in British and American corporate culture, enshrining the English language, European ethical codes, and the rational management approach to development, while the Jordanian government tends to base its norms in traditional Arab culture, emphasizing chastity, heteronormativity, family life, and abstinence from drug use.

Majhul struggles to fit the norms mandated by international donors and at times finds itself forced to change or selectively prioritize its KPs in order to align with donor definitions of a "target population" and thus sustain funding. Likewise, Majhul often alters its programming in order to fit donor norms regarding the traits that should be promoted in KPs. For instance, Majhul diverted resources from its existing HIV prevention campaigns to host violenceprevention workshops for refugee women because Majhul had received a foreign grant focused on the ties between HIV, displacement, and gender-based violence. By treating Majhul's staff and beneficiaries as biological subjects who must conform to Anglo-American norms, 
international donors sometimes bar Majhul from meeting the biosocial needs of the populations it serves. Therefore, excess enforcement of donor norms is at times violent in that it limits vulnerable populations' access to health services and the resultant health outcomes for these populations.

Power and resistance are closely related. According to Foucault (1978), power and resistance are mutually constitutive; points of resistance inevitably arise throughout a social system in response to the exertion of power. Lila Abu-Lughod (1990) defines power in terms of resistance, suggesting that resistance occurs at the intersection of overlapping spheres of power. Along these lines, Majhul resists the power exerted upon it by the Jordanian government and international funders by simultaneously maintaining healthy relationships with each of these groups, using its management's personal ties to government ministries and donor organizations as a source of power. Another way Majhul resists is through advocacy campaigns aimed at reducing stigma and communicating its core beliefs. These campaigns include the production and distribution of media about KPs, training on HIV transmission and prevention for donors, bureaucrats, and other community members, and meetings with Jordanian cultural, political, and religious leaders. Through these campaigns, Majhul resists government and donor discourse that promotes a siloed, medicalized approach to HIV prevention by instead highlighting the links between HIV, structural violence, health, and human rights.

The dynamics of these relationships between funding, power, and advocacy are illustrated well by two projects Majhul was implementing, at times simultaneously, during my fieldwork period. One of these projects was funded by a European nonprofit, which I will call HELISOC, while the other was funded by a Global Fund affiliate. In the rest of this paper, I use case studies from each of these projects to illuminate and compare manifestations of biopower in NGO-donor partnerships.

\section{Case Study I: The HELISOC Grant}

HELISOC has a branch in Jordan that provides aid to Syrian refugees and other vulnerable populations. As part of its gender-based violence (GBV) prevention campaign, the HELISOC Jordan office offered Majhul funding to help pay the salaries of its employees and hire new staff. In return, HELISOC required Majhul to host GBV education workshops and support groups. Majhul served as a valuable implementing partner for HELISOC because it had connections within the communities HELISOC was trying to reach, as many of Majhul's KPs disproportionately face GBV.

HELISOC set primarily quantitative targets for each KP it wanted Majhul to reach, and then Majhul hosted GBV workshops for the targeted populations. Many KP members sought out additional services from Majhul after attending the workshops. Majhul then referred some of these attendees back to HELISOC, thus helping HELISOC Jordan reach the numerical targets set by its European donors. In this sense, HELISOC Jordan paid Majhul as a subcontractor to bring in the KPs HELISOC needed. Majhul's funding was contingent on the adoption of HELISOC's qualifiers of success and the referral of desired KP members to HELISOC Jordan. HELISOC and Majhul called the referred members "beneficiaries," presuming that they could benefit from the provided services. Yet, in addition to being presumed beneficiaries of HELISOC and Majhul, the referred populations became products that Majhul provided to HELISOC in exchange for funding.

The Majhul-HELISOC partnership required Majhul's staff to work within the HELISOC case management framework. "Case management" was a term used by HELISOC to describe the collection of beneficiary information via interviews and the subsequent linkage of beneficiaries to social support services. I sat in on a case management training session that HELISOC hosted at Majhul. A social worker who plays a role at Majhul analogous to case management attended the training and was asked to participate in a mock case management interview. The Majhul employee was criticized by HELISOC's staff for asking interview questions not directly related to GBV.

This vignette elucidates how biopower manifested in HELISOC's relationship with Majhul. While the HELISOC training was not mandatory for Majhul staff, the structural 
power (Closser 2010) that HELISOC held as a source of funding put pressure on Majhul's social worker to attend. During the training, HELISOC portrayed the "model beneficiary" as a case where GBV can be assessed and managed separately from the beneficiary's other characteristics and challenges. In doing this, HELISOC imposed a norm that workers should only ask about the aspects of a beneficiary's life that directly relate to GBV. This norm parallels HIV exceptionalism in that it views GBV in a silo separate from other health issues and socioeconomic contexts.

After the training, the Majhul employee told her coworker about her mock interview and the HELISOC workers' critique of it. They both seemed upset by HELISOC's ignorance of how various aspects of beneficiaries' lives interrelate and are therefore important to GBV prevention. They were frustrated with the HELISOC case managers' product-oriented approach to social work, in which the product was defined as a beneficiary who had been "corrected" of their struggles with GBV via the HELISOC case management framework. Beneficiaries who had been helped in other ways were not valued as products. This strict definition of the "model beneficiary" clashed with Majhul's emphasis on the links between human rights, development, and health.

HELISOC's management sought to generate "model beneficiaries" by subjecting KPs at Majhul to the case management framework. They offered financial incentives to beneficiaries who Majhul referred directly to HELISOC, and then they assigned each of these beneficiaries a HELISOC case manager who displaced the role of Majhul's social work staff. Foucauldian biopower manifested in HELISOC's product-oriented approach to social work, as HELISOC worked through Majhul to define and promote ideal traits in biological subjects (beneficiaries) with the intent to create biological products (model beneficiaries) that fit a specific, predetermined norm ("corrected" of GBV through the HELISOC case management framework). HELISOC management also sought to transform Majhul's social workers into "model case managers." They posted flyers depicting the "proper" way to counsel a beneficiary according to the case management framework on the walls of Majhul's social work offices. Furthermore, they imposed an Englishlanguage referral system on Majhul, even though, for the most part, neither Majhul's nor HELISOC's staff were proficient in English. Therefore, inputting beneficiary information into the English-language HELISOC referral forms proved to be a cumbersome task for everyone involved.

Majhul's staff resisted HELISOC's power by quietly asserting that their focus on structural violence, human rights, and the social determinants of health served beneficiaries better than the HELISOC case management framework. For instance, the Majhul employee in the prior vignette resisted by suggesting that various aspects of beneficiaries' lives interrelate, thus drawing criticism from HELISOC's staff. Rather than backing down under this criticism, she asserted that she had been right in asking a wide variety of questions. Majhul leadership also gently pushed back against HELISOC through advocacy campaigns. These tensions over the terms of engagement were recurrent throughout Majhul's relationships with many of its other donors.

The HELISOC grant ended in late June, causing a dramatic reduction in Majhul's funding. As a result, Majhul's staff morale and capability to host programming for beneficiaries were severely hurt. Four of Majhul's seven full-time employees either quit, finished their contracts, or were laid off, and Majhul ended all of its GBV-related programming. Majhul's turbulent relationship with HELISOC is indicative of how its partnerships are constantly shifting as funders' priorities change. Majhul's management seemed cognizant of their vulnerability to the decisions of HELISOC and other foreign donors. In the words of Majhul's executive officer, "As you know, my project is maybe finished at month six, the HELISOC project. We don't decide whether the project is renewed or not."

I shared a particularly heart-wrenching moment with Majhul's manager in mid-July, a few weeks after the HELISOC funding had been cut. While we were talking, he told me out of the blue, "we're trying to keep Majhul open despite the challenges and difficulties." While HELISOC's short-term, heavily earmarked grant 
had allowed Majhul to expand its programming and delve into GBV prevention for a brief period, its abrupt termination resulted in Majhul losing staff and beneficiaries losing access to services almost overnight. By subjecting Majhul's staff and beneficiaries to strict norms that defined a "model" product of the GBV grant, HELISOC had enforced a brittle, heavily siloed care system at Majhul. This system collapsed as soon as the flow of funding from HELISOC earmarked for GBV prevention dried up.

The Majhul-HELISOC partnership and its abrupt end illustrates biopower's presence in NGO-donor relationships. Through its GBV prevention grant, HELISOC established a system in which Majhul's beneficiaries became a biological product provided to HELISOC in exchange for funding. HELISOC enforced a rigid norm of the "model beneficiary" product that Majhul should provide by seeking specifically to correct beneficiary challenges with GBV via a heavily siloed case management framework. Biopower deconstructs the process by which HELISOC defined its biological subjects as "target populations," the traits it sought to promote in those subjects as GBV-prevention strategies, and the biological products it sought to create as "model beneficiaries." Although Majhul's staff resisted these norms, HELISOC's power came to define Majhul's operations to the point that Majhul's programming all but collapsed when HELISOC left.

\section{Case Study II: The Global Fund Grant}

A different genre of international donors seeks to check the negative impacts of power imbalances in NGO-donor partnerships by empowering local populations to self-advocate. In doing this, they make NGO workers into a new type of biological subject by defining their return on investments not only in terms of "beneficiaries" reached but also in terms of grassroots research and advocacy.

One of these donors is currently working through the Global Fund to provide Majhul with a grant for advocacy for and research on populations at risk of HIV transmission. Instead of being earmarked for providing specific services to KPs, this grant has the overarching mandate to help Majhul advocate for the programming necessary to stop HIV's spread, thus increasing the sustainability of Majhul's full range of services. The Global Fund grant more closely aligns with Majhul's mission than the HELISOC grant, as it trades in the siloed approaches of HELISOC and the World Bank for a holistic approach that directly addresses the rights of KPs; its mission statement includes the reduction of "human rights-related barriers" to AIDS prevention. The grant funds two lines of work: advocacy for the rights of KPs and research on the barriers KPs face to accessing health services. It therefore measures success in terms of the quality of Majhul's advocacy programs and the body of research Majhul produces on its KPs.

By funding advocacy work, the Global Fund grant empowers and encourages Majhul to resist its other donors. I saw this dynamic in action when I attended a Majhul training session funded by the grant. The training's target audience was management from Majhul's partner organizations, including HELISOC. Its goal was to shed light on the various ways in which HIV ties into social issues important to donors. Majhul's manager centered the training's afternoon workshop on the links between structural violence, human rights abuses, and HIV transmission. He received resistance from some of the more conservative audience members, which he successfully worked through while avoiding confrontation and maintaining his emphasis on the rights of KPs. For instance, a man in the audience suggested that sex with foreigners may be the principal cause of HIV infections among Jordanians. Majhul's manager did not say that the man was wrong, but he instead insinuated that Jordanians must be having lots of sex with foreigners for this to be a principal cause. This discourse indicates that Majhul's manager held a degree of power over donors who attended the training session, as he could push back against the audience's resistance to points that he made. He could therefore engage the donors who attended in a dialogue about Majhul's values and priorities.

Majhul's manager incorporated the importance of health as a human right by asserting that stigma impedes the right to health of sex workers, MSM, and people living 
with HIV. He also told the audience that not all gay men have sex with other men, and he explained how structural violence puts women at a greater risk than men of contracting HIV. By making these points, he argued that HIV transmission is more closely linked to structural violence and human rights violations than to individual promiscuity or poor decision-making. In emphasizing the links between marginalization, structural violence, and HIV transmission, Majhul's manager resisted the siloed approach to health and development that organizations like HELISOC and the World Bank have used. The training was at heart an attempt by Majhul's management to increase the propensity of donors focused on gender equity, social welfare, and human rights to fund a center dedicated to HIV prevention.

The Global Fund grant also called for Majhul's staff to conduct original research on their KPs. Many donors, including HELISOC, collected both quantitative and qualitative data on Majhul's KPs, but the Global Fund grant was unique in that it gave Majhul the power and responsibility to conduct research on its own terms. Majhul used the grant to conduct four focus groups in its drop-in center, each one for a different KP. One of Majhul's employees explained to me that Majhul would use the data from the focus groups to write reports for the Global Fund about the barriers KPs and other marginalized populations face to accessing services with the ultimate goal of making Majhul's services more accessible. Majhul recruited a lawyer with a specialty in Jordanian HIV law and a woman who had previously worked with Majhul and the National Program to Combat AIDS to help with the focus groups. Majhul depended on its network of outreach workers to recruit participants for the groups.

The Global Fund shifted the balance of power towards Majhul throughout the research process. For instance, Majhul did not submit its concept note for the focus groups until after it had conducted them. A concept note is an abridged grant proposal summarizing the proposed project, so it's usually one of the first steps of the logical framework. Since Majhul didn't submit the concept note until after it had used Global Fund grant money to host the focus groups, the Global Fund must have entrusted Majhul with some funding when the research plan was still malleable. This flexibility empowered Majhul's staff to run the focus groups how they thought best instead of strictly adhering to a pre-agreed upon logical framework.

Majhul's staff not only collected data during the focus groups but also framed research questions, developed a methodology, and drew conclusions from their results. There was no Global Fund representative monitoring the groups; I was the one non-Jordanian present. The Global Fund received only the final products of the research Majhul conducted. Majhul's staff were therefore empowered to determine which findings from the focus groups were pertinent to report to the Global Fund. However, Majhul lacked complete autonomy in the reporting process, as the Global Fund required that third party mapping consultants help consolidate the final reports.

While this partial ownership over the knowledge generation process marked a shift in power towards Majhul's staff, it also turned Majhul's staff and beneficiaries into a new type of biological subject. The Global Fund set norms regarding a "model" beneficiary and "model" staff member when it allocated grant money to grassroots research on Majhul's beneficiaries. The "model" beneficiary provided compelling testimony about the barriers they faced to accessing health services, while the "model" staff member actively solicited this testimony with the intention to generate research that could be used for future advocacy and program development. The Global Fund therefore paralleled HELISOC in that it defined and promoted ideal traits in biological subjects (Majhul's beneficiaries and staff) with the intent to create biological products ("model" beneficiaries and staff) that fit a norm (autonomously facilitating the research process) which served the Global Fund's goals. However, the Global Fund differed from HELISOC in that grassroots empowerment and ownership were key criteria of its biological subjectivity, so it allowed Majhul's staff more freedom to choose how they would create or become model biological subjects.

The Global Fund had a strong incentive to make Majhul's staff into partially autonomous 
researchers: past ethnographic research indicates that qualitative data quality improves when "insiders" from the local community facilitate social science research. Insiders often can frame questions in a more culturally sensitive manner, and they possess credibility that enables them to elicit more honest or in-depth responses from research subjects (Baker and Hinton 2011). Through the focus groups, Majhul's beneficiaries were able to freely voice their opinions, ideas, and frustrations without foreign supervision coloring their responses. The Global Fund reaped the benefits of this research, as it received Majhul's reports on each focus group's findings, which it could use to better understand how to fund future HIV prevention efforts in Jordan.

\section{Implications of Biopower's Manifestation in Majhul's Partnerships with Donors}

As the HELISOC and Global Fund case studies show, donors in the fields of global health and development create biological subjects out of the populations they serve. For NGOs in the MENA region, access to funding is often contingent on the production of a biological product that fulfills donor norms. Donors view their donations as investments and assess return on their investments in terms of their grants' abilities to generate a "model" biological product. The raw materials for this biological product are donor-determined target populations, which necessarily become synonymous with the "KPs" that their implementing partners serve. For instance, Majhul's KPs were largely determined by Majhul's donors; Syrian refugee women became a KP for Majhul because HELISOC listed Syrian refugee women as a target population for their GBV prevention grant. Donors use terms like "implementing partner" and "beneficiary" to describe the type of biological product they expect to receive. They work through partners like Majhul by providing funds with certain conditions attached to implement programs that will transform KPs into beneficiariespopulations who benefit from the imposition of donor norms.
Key international donors have responded to critiques of the strict upward accountability that comes alongside rational management by turning to broader project implementation frameworks, such as the Theory of Change framework, which cites the logical framework as just one of the tools to be used for monitoring project success (Rogers 2014). However, biopower manifests in even the most flexible of NGO-donor partnerships, as all grant-funded global health projects with a pre-agreed upon framework create biological subjects such as "implementing partners," "target populations," "key populations," or "beneficiaries." These biological subjects must achieve predetermined norms for the NGO-donor partnership to be considered a successful investment.

The HELISOC grant reflected many of Majhul's other grants in that it imposed a siloed approach to development onto Majhul through its case management framework. HELISOC worked through Majhul to provide a specific service, GBV prevention, to specific KPs until predetermined targets were met. In this system, beneficiaries became a product whose value was determined by their ability to fulfill the rigid biological norms set by HELISOC's siloed approach. Therefore, HELISOC's beneficiary referral system with Majhul reveals how NGO partnerships can warp into client-like relationships where KPs become a currency to be exchanged between grantor and grantee. The "beneficiaries" become the product, and their ability to exhibit (or not exhibit) certain traits marks their value. HELISOC had tremendous power to determine the "model" biological subject, whereas Majhul held barely any power. This produced an unsustainable, product-based system that collapsed as soon as HELISOC's funding ended.

Biopower necessarily manifests in NGOdonor partnerships, but it only becomes violent when donors set strict and unrealistic norms in defining their "model" biological product. The Global Fund grant stands out as an example of a nonviolent manifestation of biopower in a project intended to empower grassroots NGOs and promote innovation. The grant defines its "model" biological product as KP representatives and allies who are empowered to self-advocate and design their own programming. Accordingly, it replaces 
traditional rational management theory with a more flexible evaluation process, allowing Majhul's staff leeway to conduct advocacy and research as they see fit. The Global Fund grant does this because its originators view empowered KP representatives and allies as the building blocks of sustainable programming.

Biopower manifested in both the HELISOC grant and the Global Fund grant, but HELISOC differed from the Global Fund in that it enforced its norms more strictly, permitting little deviation from the at times unrealistic biological products it expected Majhul to provide. HELISOC's strict adherence to the rational management approach impeded Majhul's ability to sustainably serve its KPs, especially because it was paired with a siloed approach to GBV prevention in which only a small portion of the potential beneficiary population was valued. HELISOC's inflexibility therefore contributed to structural violence against KPs because it barred certain KPs from accessing resources they needed to stay healthy. This is a recurrent issue with siloed grants that demand specific biological products; strict enforcement of donor norms prevents NGOs from sustainably serving both donordefined KPs and other potential beneficiaries (Hummelbrunner 2010; Nguyen 2010; Wallace, Bornstein, and Chapman 2007).

Notably, the presence of biopower in Majhuldonor partnerships parallels the power dynamics between NGOs like Majhul and their beneficiaries. Majhul is itself a powerful actor in the space of HIV/AIDS that designates its own KPs and thus creates its own biological subjects. Therefore, biopower manifests in Majhul's relationship with its beneficiaries. Along these lines, Majhul attaches various stipulations to the services it provides; many of these stipulations trickle down from Majhul's donors. For instance, beneficiaries could only receive cash transfers from Majhul if they participated in multiple trainings and interviews with both Majhul and HELISOC. Given the powerful position Majhul holds vis-à-vis its beneficiaries, one would assume that its politics and practices must be met with resistance at times. Due to the limitation of my own research and my decision to focus on Majhul's staff instead of its beneficiaries, I cannot fully explore the implications of these power dynamics here. The nuance and complexity of beneficiaries' relationships with Majhul warrant future research, including explorations of how beneficiaries navigate Majhul's stipulations regarding service provision and how they resist Majhul's exertion of power.

\section{Conclusion}

In accordance with Foucault's theory of biopower, donors create biological subjects out of NGO staff and beneficiaries by setting norms that NGOs must follow to maintain funding. At times, they bar NGOs from meeting the biosocial needs of potential beneficiaries by strictly defining the "model" biological product they expect NGOs to provide. Therefore, the rigid enforcement of donor norms sometimes becomes violent in that it impedes vulnerable populations' access to health services and the resultant health outcomes for these populations. This was the case for the HELISOC grant, which forced an unsustainable beneficiary care system onto Majhul by mandating a strict, siloed case management framework. The Global Fund defined its model biological product as a KP representative or ally who could innovate and self-advocate. It therefore imbued its grant with more flexibility than the HELISOC grant and avoided much of the violence that results from rigid norm enforcement. Yet, it nevertheless held power as the funding source in its relationship with Majhul; benevolent power is still power.

Exploring the nuances of these NGO-donor relationships allows us to situate each of Majhul's successes and challenges within theories of power. Many NGOs supporting marginalized groups in the developing world rely on foreign donors because they face a lack of local financial support. Therefore, they find themselves compelled to follow global development funding norms set by Europeans and Americans. One of the most pervasive of these norms is the rational management approach, which measures return on donor investments according to success indicators assessed through monitoring and evaluation. Oftentimes, NGOs struggle to meet stringent demands of donors lacking understanding of local customs, needs, and priorities. 
Importantly, Majhul exemplifies the thousands of developing world NGOs that rely on international funding. These NGOs are caught between two worlds, that of their donors and that of their beneficiaries. Herein lies the crux of my argument: these NGOs are never fully autonomous. Their services are constrained by national and global structures that give governments and foreign actors a disproportionate amount of power over civil society in developing countries.

There are substantial gaps in current knowledge of development practices in the MENA region. Additional ethnography on NGOs serving marginalized groups in MENA, especially HIV prevention NGOs, would help to contextualize Majhul's challenges and develop new theoretical frameworks for understanding HIV prevention in the Arab world. 


\section{Acknowledgements}

I thank Dr. Fida Adely (Georgetown University CCAS) and Dr. Emily Mendenhall (Georgetown SFS STIA Department) for their mentorship throughout the research process. I also thank my Arabic teachers at Georgetown and CET Jordan for helping me develop the language skills needed to conduct ethnographic research in Jordan. Finally, I thank the many Jordanian friends and allies who supported me throughout the research process. This work was made possible by the Lisa J. Raines Fellowship. 


\section{References}

Abu-Lughod, Lila. 1990. "The Romance of Resistance: Tracing Transformations of Power Through Bedouin Women." American Ethnologist 17 (1): 41-55.

Abu-Raddad, Laith J., Nahla Hilmi, Ghina Mumtaz, Manal Benkirane, Francisca Ayodeji Akala, Gabriele Riedner, Oussama Tawil, and David Wilson. 2010. "Epidemiology of HIV Infection in the Middle East and North Africa." AIDS24 (Suppl 2): S5-23. https:// doi.org/10.1097/01.aids.0000386729.56683.33.

Alkaiyat, Abdulsalam, Christian Schaetti, Mohammad Liswi, and Mitchell G. Weiss. 2014. "Condom Use and HIV Testing among Men Who Have Sex with Men in Jordan." Journal of the International AIDS Society 17 (1): 18573.

Al-Khasawneh, Esra, Leyla Ismayilova, Hmoud Olimat, and Nabila ElBassel. 2012. "Social and Behavioural HIV/AIDS Research in Jordan: A Systematic Review." Eastern Mediterranean Health Journa/18 (5): 487-494.

Al-Khasawneh, Esra, Leyla Ismayilova, Vidya Seshan, Olimat Hmoud, and Nabila El-Bassel. 2013. "Predictors of Human Immunodeficiency Virus Knowledge among Jordanian Youths." Sultan Qaboos University Medical Journa/13 (2): 232-240.

Al-Khasawneh, Esra, Willi McFarland, Jeffery Mandel, and Vidya Seshan. 2014. "Insight into Jordanian Thinking About HIV: Knowledge of Jordanian Men and Women About HIV Prevention." Journal of the Association of Nurses in AIDS Care 25 (1): e1-9.

Baker, Rachel, and Rachel Hinton. 1999. “Do Focus Groups Facilitate Meaningful Participation in Social Research?" In Developing Focus Group Research, edited by Rosaline S. Barbour and Jenny Kitzinger, 79-98. London: SAGE Publications Ltd.

Basilico, Matthew, Jonathan Weigel, Anjali Motji, Jacob Bor, and Salmaan Keshavjee. 2013. "Health for All? Competing Theories and Geopolitics." In Reimagining Global Health: An Introduction, edited by Paul Farmer, Arthur Kleinman, and Jim Yong Kim, 74110. Berkeley: University of California Press.

Baylouny, Anne Marie. 2008. "Militarizing Welfare: Neo-Liberalism and Jordanian Policy." Middle East Journal 62 (2): 28.

Benton, Adia. 2015. HIV Exceptionalism: Development Through Disease in Sierra Leone. Minneapolis: University of Minnesota Press. 
Bornstein, Lisa. 2006. "Systems of Accountability, Webs of Deceit? Monitoring and Evaluation in South African NGOs." Development 49 (2): 52-61.

Closser, Svea. 2010. Chasing Polio in Pakistan. 1st ed. Nashville: Vanderbuilt University Press.

Das, Pamela, and Richard Horton. 2018. "Beyond the Silos: Integrating HIV and Global Health." The Lancet 392 (10144): 260261.

DeJong, Jocelyn. 1995. "Households, Health and Crises: Coping with Economic Upheaval in Jordan, 1988-1991." Journal of International Development 7 (3): 443-465.

Ebrahim, Alnoor. 2002. "Information Struggles: The Role of Information in the Reproduction of NGO-Funder Relationships." Nonprofit and Voluntary Sector Quarterly31 (1): 31.

El-Said, Hamed, and Jane Harrigan. 2014. “Economic Reform, Social Welfare, and Instability: Jordan, Egypt, Morocco, and Tunisia, 1983 -2004." The Middle East Journal 68 (1): 99-121.

Farmer, Paul. 2003. Pathologies of Power: Health, Human Rights, and the New War on the Poor. Berkeley: University of California Press.

Foucault, Michel. 1978. The History of Sexuality English Translation. New York: Random House, Inc.

“Global AIDS Response Progress Reporting: Country Progress Report Hashemite Kingdom of Jordan." 2014. UNAIDS, 2014 Progress reports submitted by countries. https://www.unaids.org/sites/ default/files/country/documents/JOR_narrative_report_2014.pdf.

Grépin, Karen A. 2012. "HIV Donor Funding Has Both Boosted and Curbed the Delivery of Different Non-HIV Health Services In SubSaharan Africa." Health Affairs 31 (7): 1406-1414.

Hummelbrunner, Richard. 2010. "Beyond Logframe: Critique, Variations and Alternatives." In Beyond Logframe: Using Systems Concepts in Evaluation, edited by Nobuko Fujita, 1-33. Tokyo: Foundation for Advanced Studies on International Development.

Kumaranayake, Lilani. 1998. "Effective Regulation of Private Sector Health Service Providers." Working Paper, Department of Public Health and Policy at London School of Hygiene and Tropical Medicine. https://citeseerx.ist.psu.edu/viewdoc/download? doi=10.1.1.201.5173\&rep=rep1\&type=pdf. 
Mann, Jonathan M., Lawrence Gostin, Sofia Gruskin, Troyen Brennan, Zita Lazzarini, and Harvey V. Fineberg. 1994. "Health and Human Rights." Health and Human Rights 1 (1):18.

Marnicio, Ariana. 2016. "Advancing HIV Preventative Health Care for Adolescents: The Case of Jordan." Working Paper, James A. Baker III Institute for Public Policy of Rice University. https:// hdl.handle.net/1911/91820.

Mueller-Hirth, Natascha. 2012. "If You Don't Count, You Don't Count: Monitoring and Evaluation in South African NGOs: Monitoring and Evaluation in South African NGOs." Development and Change 43 (3): 649-670.

Mumtaz, Ghina R., Gabriele Riedner, and Laith J. Abu-Raddad. 2014. "The Emerging Face of the HIV Epidemic in the Middle East and North Africa." Current Opinion in HIV and AIDS9 (2): 183-191.

Nawafleh, Hani, Karen Francis, and Ysanne Chapman. 2005. “The Influence of HIVIAIDS on the Practice of Primary Care Nurses in Jordan: Rhetoric and Reality." International Journal of Nursing Practice 11 (5): 200-205.

Nguyen, Vinh-Kim. 2010. The Republic of Therapy: Triage and Sovereignty in West Africa's Time of AIDS. Durham: Duke University Press Books.

Packard, Randall. 2016. A History of Global Health. Baltimore: Johns Hopkins Press.

Porter, Gina. 2003. “NGOs and Poverty Reduction in a Globalizing World: Perspectives from Ghana." Progress in Development Studies 3 (2): 131-45.

Quinn, Dilys, Radwan Shaban, John Speakman, Thirumalai Srinivasan, and Sophie Warlop, eds. 2001. "Privatization: The Jordanian Success Story." The World Bank Group Jordan Country Unit, October 2001. https://documents1.worldbank.org/curated/ en/874571468040536834/ pdf/371150JO0quart1 te03rd0200101PUBLIC1.pdf.

Reith, Sally. 2010. "Money, Power, and Donor-NGO Partnerships." Development in Practice 20 (3): 446-455.

Rogers, Patricia. 2014. Theory of Change. Vol. 2. Methodological Briefs: Impact Evaluation. Florence: UNICEF Office of Research.

Uvin, Peter. 2004. Human Rights and Development. Bloomfield, CT: Kumarian Press. 
Walker, Liz. 2017. "Problematising the Discourse of 'Post-AIDS."” Journal of Medical Humanities 41: 95-105.

Wallace, Tina, Lisa Bornstein, and Jennifer Chapman. 2007. The Aid Chain: Coercion and Commitment in Development NGOs. Rugby: Practical Action Pub.

Wiktorowicz, Quintan. 2002. "The Political Limits to Nongovernmental Organizations in Jordan." World Development 30 (1): 77-93.

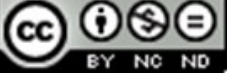

This work is licensed under a Creative Commons

Attribution-NonCommercialNoDerivatives

4.0 International License. 